\title{
PARIMOS EM PORTUGAL: A VIVÊNCIA DO SERVIÇO DE SAÚDE POR IMIGRANTES BRASILEIRAS
}

\author{
GIVING BIRTH IN PORTUGAL: THE EXPERIENCE OF BRAZILIAN \\ IMMIGRANTS USING THE HEALTH SERVICE
}

\section{Eliany Nazaré Oliveira', Roberlândia Evangelista Lopes ${ }^{2}$, Maria Michele Bispo Cavalcante ${ }^{3}$, Tamires Alexandre Felix ${ }^{4}$, Félix Neto ${ }^{5}$, Roberta Magda Martins Moreira ${ }^{6}$}

'Enfermeira. Docente na Universidade Estadual Vale do Acaraú. Sobral, Ceará, Brasil. elianyy@hotmail.com 2Enfermeira, Mestre. Professora das Faculdades INTA, Sobral, Ceará, Brasil. roberlandialopes@hotmail.com ${ }^{3}$ Enfermeira, Mestre. Professora das Faculdades INTA, Sobral, Ceará, Brasil. michellebispoc@yahoo.com.br ${ }^{4}$ Enfermeira. Mestra em Saúde da Família. Sobral, Ceará, Brasil. myrisinha@hotmail.com ${ }^{5}$ Psicólogo. Professor Catedrático da Faculdade de Psicologia e Ciências da Educação da Universidade do Porto. Porto, Portugal.fneto@fpce.up.pt ${ }^{6}$ Acadêmica de Enfermagem na Universidade Estadual Vale do Acaraú. Sobral, Ceará, Brasil. robertamoreiraenf@hotmail.com

RESUMO | Objetivou-se narrar as experiências da assistência em saúde durante $\circ$ parto de imigrantes brasileiras que vivem em Portugal. Abordagem qualitativa com o método Netnográfico constituiu a metodologia. A comunidade de escolha foi um grupo do Facebook - brasileiras que vivem em Portugal- e a coleta das informações ocorreu durante o fórum de discussão: "Parimos em Portugal, relatando a minha experiência". Nos resultados emergiram 04 temáticas e 08 categorias de analise. A maioria das experiências das mulheres brasileiras evidenciaram os aspectos positivos do parto e dos serviços e um pequeno grupo revelou os entraves e aspectos negativos. Destaca-se a necessidade de conhecimento com mais detalhes dos itinerários de imigrantes grávidas e os desfechos sobre seus partos, para assim, implementar ações de apoio a este grupo. Sugere-se a criação de um observatório sobre prénatal, parto e puerpério de imigrantes brasileiras sob a coordenação do Consulado do Brasil em Portugal.

Palavras-Chave: Emigração e Imigração; Serviços de Saúde da Mulher; Parto.

\begin{abstract}
The objective of this study was to describe the experience of health care during childbirth of Brazilian immigrants living in Portugal. This study used a qualitative approach with ethnographic methods. The community of choice was a Facebook group - Brazilians living in Portugal - and information was collected during the discussion forum: "Giving birth in Portugal, reporting my experience". From the results 04 thematic and 08 analysis categories emerged. Most of the experiences of the Brazilian women showed the positive aspects of childbirth and the services, and a small group revealed the obstacles and negative aspects. It is important to emphasize the need for more detailed knowledge on the itineraries of pregnant immigrant women and the outcomes of their childbirth, so as to implement actions to support this group. We suggest the creation of an observatory for prenatal, delivery and postpartum care for Brazilian immigrants under the coordination of the Brazilian Consulate in Portugal.
\end{abstract}

Keywords: Emmigration and Immigration; Women's Health Services; Parturition. 


\section{INTRODUÇÃO}

Portugal vem com o passar dos anos se caracterizando por um país de imigração. $O$ crescente número de estrangeiros residentes em Portugal configura-se numa crescente, entre eles os brasileiros. Referente a esse grupo o Serviço de Estrangeiros e Fronteiras' afirma que a população brasileira com vistos oficiais em Portugal totalizou 87.493 indivíduos (53.537 mulheres e 33.956 homens). Vale ressaltar que esses dados referem-se aos indivíduos em situação legal, sem estimar a quantidade real de brasileiros que vivem no país, uma vez que, muitos se encontram em situação ilegal.

Em 2015, ○ Itamaraty contabilizou 162.190 brasileiros residentes em Portugal, o que demonstra que o processo imigratório é constante. Desse grupo, destacam-se as mulheres, pois estão em maior número e se particularizam pelo ciclo especifico de gestação-natalidade em terra estrangeira $\circ$ que envolve processos legais, mas para além disso, a assistência à saúde no sistema português.

Antes de se deter as nuances envolta do ato de parir, destaca-se que a Organização Mundial de Saúde ${ }^{2}$ determina que todas as mulheres têm direito ao mais alto padrão de saúde atingível, incluindo o direito a uma assistência digna e respeitosa durante toda a gravidez e o parto, assim como o direito de estar livre da violência e discriminação de qualquer natureza.

Tal orientação tem uma relação direta com a forma de perceber a saúde reprodutiva como uma das principais preocupações da saúde pública internacional. É possível afirmar que dinâmicas complexas e múltiplas em um processo migratório pressupõe constituir fatores de vulnerabilidade para o estado de saúde/doença dos indivíduos ${ }^{3}$. Ainda refere-se que as mulheres imigrantes continuam a ter uma exposição desigual em face de potenciais riscos, entre eles, as práticas discriminatórias, tráfico, mutilação genital, trabalho doméstico que obviamente trazem consequências ao seu estado de saúde, situação que se agrava claramente num contexto de gravidez (violência nas relações, aborto).

Discutido este ponto, há de se questionar como se dá o acesso e assistência à saúde das mulheres imigrantes brasileiras grávidas em Portugal, em especial, parturientes. Como ocorre essa assistência? Quais os desafios e avanços sentidos pelas imigrantes brasileiras?

Para isso, aponta-se que Portugal, em 2001, tomou uma importante decisão no sentido de garantir assistência universal aos serviços de saúde pelas populações imigrantes com a publicação do Despacho n. ${ }^{\circ} 25.360 / 2001^{4}$. Com este, o imigrante em situação regular pode utilizar, tal como os portugueses, os serviços de saúde oficiais através do cartão de utente concedido a quem apresentar a autorização de permanência ou residência ou o visto de trabalho. Os imigrantes sem documentos têm acesso a um cartão temporário de utente apresentando um documento da Junta de Freguesia da sua área de residência que certifique que se encontra morando em Portugal há mais de noventa dias. Vale ressaltar que os brasileiros podem, também, ter acesso ao serviço de saúde, a partir do Acordo de Segurança Social/Seguridade Social entre Brasil e Portugal de 1995.

O Acordo proporciona ao cidadão brasileiro que chegar a Portugal, como turista ou com visto temporário ou de residência, direito à assistência médico-hospitalar (de emergência ou regular) e mesmo à aquisição de medicamentos. Esta normativa também firma $\circ$ acompanhamento e vigilância da mulher durante a gravidez, parto e puerpério e cuidados de saúde prestada aos recém - nascidos.

De acordo com dados do Relatório sobre as Desigualdades na Saúde na União Europeia ${ }^{5}$, Portugal tem a sexta mais baixa taxa de mortalidade infantil da União Europeia.

Em 2012, a taxa de cesarianas em Portugal foi de $35,56 \%$, sendo nos hospitais públicos de $30,99 \%$ e nos hospitais privados de $67,48 \%(13,11 \%$ dos partos ocorrem em hospitais privados). Portugal é assim um dos países europeus com maior taxa de cesarianas, sendo ultrapassado apenas pela Itália e a Turquia. Na maioria dos países europeus a taxa de cesarianas não ultrapassa os $30 \%$ e vários têm uma taxa inferior a $20 \%{ }^{\circ}$. 
Feitas essas ponderações, se dá o direito da narrativa às mulheres imigrantes brasileiras na perspectiva de descortinar as suas vivências pelo serviço de saúde de Portugal, especificamente as suas experiências pela atenção recebida ao momento de parturição.

Desta forma é possível compreender os ramos da atenção à saúde nesta situação específica melhorando a capacidade de discernir sobre residir ou não em outro país, no caso Brasil-Portugal, considerando a saúde ponto relevante para a decisão. Além disso, a proposta viabiliza discussões no consulado para apoio às mulheres em condição de imigração que necessitam destes serviços no que se relaciona a saúde reprodutiva.

Assim, o objetivo desta pesquisa é discutir a narrativa de imigrantes brasileiras que vivem em Portugal sobre as experiências de assistência em saúde no período do parto.

\section{MÉTODO}

- método Netnográfico serviu de aporte metodológico para esse estudo. Autores ${ }^{7}$ afirmam que nesse tipo de investigação o pesquisador deve permanecer consciente de que está observando um recorte comunicacional das atividades de uma comunidade on-line.

A comunidade de escolha foi um grupo da rede social Facebook - BRASILEIRAS QUE VIVEMEM PORTUGAL. Este foi criado em março de 2016 pela primeira autora do artigo, durante o desenvolvimento do seu Pós Doutoramento na Faculdade de Psicologia e Ciências da Educação da Universidade do Porto. A principal motivação para criação do grupo foi a necessidade de localizar e convidar imigrantes brasileiras em Portugal a participar da pesquisa: "Estado de Saúde e Qualidade de Vida de Imigrantes Brasileiras em Portugal" mediando trocas de experiências e apoio via consulado.

Destaca-se que em agosto de 2016 o grupo já estava constituído por 1743 participantes, com uma média diária de 03 solicitações de adesão. Assim, do grupo do Facebook - BRASILEIRAS QUE VIVEM EM PORTUGAL foi instituído o fórum de discussão:
"Parimos em Portugal, relatando a minha experiência". Deste fórum, foram extraídas as narrativas sobre a vivência do parto das mulheres brasileiras imigrantes em Portugal. $O$ fórum ficou ativo durante 0 mês de julho de 2016. Nesse ambiente, foram lançados questionamentos: como foi sua experiência de parir em Portugal? Quais os desafios encontrados? E os avanços? Em todo momento, foi mediado à discussão e estimulado as participantes do grupo a se expressarem livremente. Partilhando com as demais as suas perspectivas e vivência no ato de parir em outro País, que não o Brasil.

As participantes tiveram um período de 30 dias para postarem os relatos de suas experiências sobre parto em Portugal. Um total de 65 relatos constituíram a amostra, onde cada um recebeu uma codificação BVP - brasileiras que vivem em Portugal de 1 a 65.

Os relatos das mulheres imigrantes brasileiras foram organizados com base em Minayo ${ }^{8}$, ou seja, a princípio foi feita uma leitura flutuante do material presente no fórum, após houve a exploração das narrativas com índice de profundidade mais apurado, o texto foi desdobrado e as unidades temáticas e suas respectivas categorias foram selecionadas. A interpretação se deu por meio de variante qualitativa, trabalhando com os significados e com a subjetividade envolta desse tipo de abordagem.

Enquanto extrato de uma pesquisa maior de pósdoutoramento da autora principal do artigo: Estado de Saúde e Qualidade de Vida de Imigrantes Brasileiras em Portugal salienta-se que o estudo atende os princípios éticos e foi aprovada pelo comitê de ética da Universidade Estadual Vale do Acaraú - UVA sob o Parecer $n^{\circ} 1.544 .203$, sendo norteado pela Resolução 466/129.

\section{RESULTADOS}

Com intuito de compreender as experiências da assistência em saúde durante o parto de imigrantes brasileiras que vivem em Portugal se buscou por meio da descrição e extração das falas das informantes agrupar os dados de acordo com a similaridade, em quatro temáticas a partir de suas respectivas categorias. Conforme ilustra o Quadro 1. 
Quadro 1. Experiências vivenciadas no serviço de saúde por imigrantes brasileiras em Portugal durante o parto, Portugal, 2016.

\begin{tabular}{|c|c|c|c|}
\hline$N^{\circ}$ de Relatos $=28$ & $N^{\circ}$ de Relatos $=19$ & $\mathrm{~N}^{\circ}$ de Relatos $=12$ & $N^{\circ}$ de Relatos $=06$ \\
\hline TEMÁTICA & TEMÁTICA & TEMÁTICA & TEMÁTICA \\
\hline $\begin{array}{l}\text { Tudo o que um sonho } \\
\text { precisa para ser } \\
\text { realizado é alguém } \\
\text { que acredite nele }\end{array}$ & $\begin{array}{l}\text { Não há no mundo } \\
\text { exagero mais belo } \\
\text { que a gratidão }\end{array}$ & $\begin{array}{l}\text { A diferença entre } \\
\text { sucesso e fracasso é } \\
\text { trabalho com } \\
\text { competência }\end{array}$ & $\begin{array}{l}\text { Não há nada mais } \\
\text { duro que a } \\
\text { suavidade da } \\
\text { indiferença }\end{array}$ \\
\hline CATEGORIAS & CATEGORIAS & CATEGORIAS & CATEGORIAS \\
\hline $\begin{array}{l}\text { Planejamento do } \\
\text { Parto } \\
\text { Atendimento ideal }\end{array}$ & $\begin{array}{l}\text { Acolhimento } \\
\text { Cuidado Integral }\end{array}$ & $\begin{array}{l}\text { Profissionalismo } \\
\text { Empatia }\end{array}$ & $\begin{array}{l}\text { Onde estava a } \\
\text { humanização? } \\
\text { Negação do poder } \\
\text { de decisão }\end{array}$ \\
\hline
\end{tabular}

Fonte: elaborado pelos autores.

\section{Tudo o que um sonho precisa para ser realizado é alguém que acredite nele}

Esta unidade temática apresenta experiências de partos bem sucedidos nos serviços de saúde de Portugal, relatados por imigrantes brasileiras. O poder da decisão, a acolhida e a escuta qualificada foram responsáveis pela materialização de um parto tranquilo ou menos traumático. Tais elementos apresentaram-se como fatores significativos, uma vez que possibilitaram o alcance da expectativa da gestante, ao empoderá-la, apoiá-la e auxiliá-la durante $o$ processo em que se iniciava. O momento ímpar da maternidade nesta categoria foi alcançado com a autonomia, ensejos e o mais importante "escolhas" da própria parturiente, reafirmando-a como sujeito ativo de sua vida e de seu filho.

Esta unidade temática Tudo o que um sonho precisa para ser realizado é alguém que acredite nele compreendeu vinte e oito (28) das sessenta e cinco (65) mulheres que compuseram o estudo. Conforme elucida a Figura 1 , evidenciando extratos de algumas falas das mulheres.
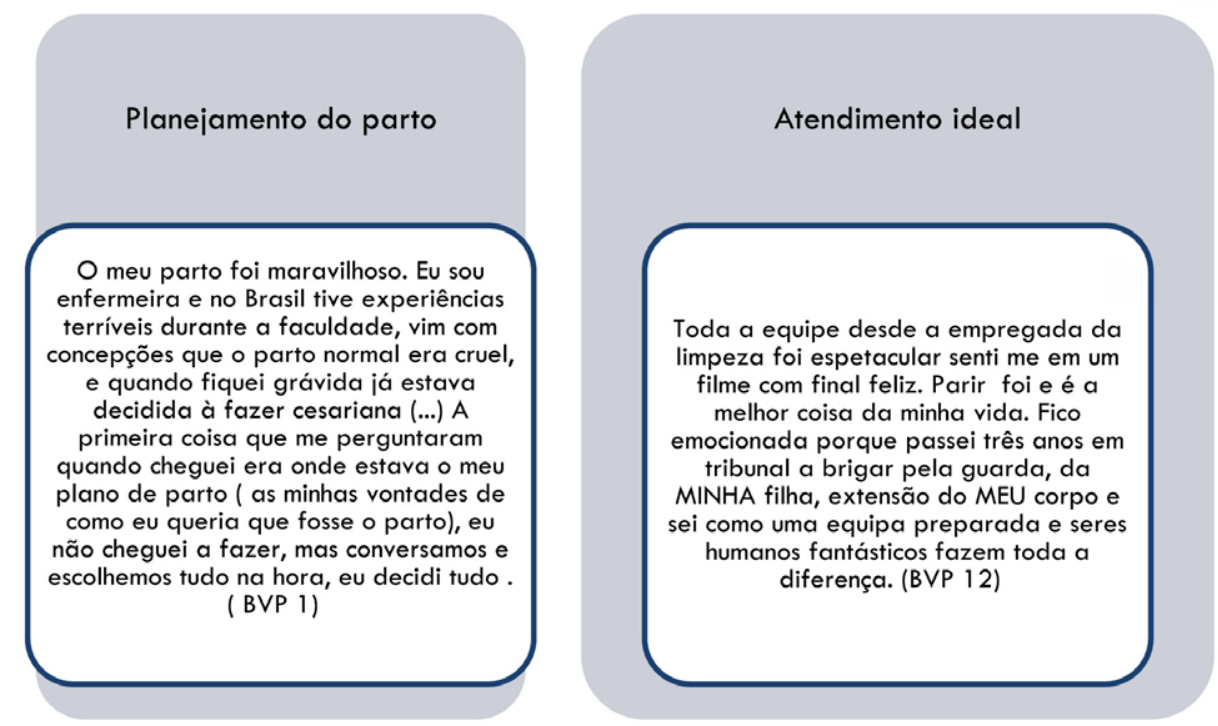

Figura 1: Categorias da unidade temática: tudo o que um sonho precisa para ser realizado é alguém que acredite nele, Portugal, 2016.

Fonte: elaborado pelos autores.

Os depoimentos indicam que houve uma satisfação com o processo de condução do parto. Mesmo vivendo em outro país, as mulheres desta categoria entenderam receberem respeito e assistência adequada. Estudo realizado anteriormente ${ }^{10}$ revelou que a preparação para $\circ$ parto influencia positivamente a percepção dos cuidados culturais durante o trabalho de parto. Nesse sentido, as políticas de saúde devem possibilitar o seu desenvolvimento nas instituições de saúde, de forma descentralizada, de modo a que todas as grávidas tenham acesso a esta preparação, independentemente do seu local de residência e da sua formação. 
As mulheres grávidas possuem expectativas, em relação ao modo como irá acontecer seu trabalho de parto, o mesmo, se encontra diretamente relacionado às suas tradições e costumes, que são transmitidos ao longo das gerações e que podem influenciar a forma como esta vai encarar tal momento ${ }^{1}$.

Não se pode deixar de anunciar que o planejamento do parto predispõe à humanização, uma vez que, se permite o protagonismo da mulher, conhecendo quais são os seus anseios, desejos e medos para este acontecimento. É poder ouvir a sua opinião e respeitar suas escolhas e, acima de tudo, é dar-lhes a devida informação para que possam tomar as suas decisões de forma consciente e informada, proporcionando a vivência do parto com autonomia. Sobre esta, entende-se como basilar à saúde e cidadania feminina, pois diz respeito à competência humana em "dar-se suas próprias leis", agir de maneira soberana em relação a si mesmo, sendo o modo de ser do humano, portanto, uma precondição para a saúde. Reiterando que o "parir" deve ser acompanhado de maneira favorável e não invasiva ${ }^{12}$.

Sobre isto, em estudo sobre Parto Normal em Portugal: a experiência de "parto na água" afirma-se que as mulheres querem que a sua gravidez e a experiência do parto sejam consensuais e participativas e é por isso que escolhem um serviço que lhes permita ter este tipo de experiência ${ }^{13}$.

\section{Não há no mundo exagero mais belo que a gratidão}

A seguinte unidade temática evidenciou um componente peculiar; nela, observou-se que o termo gratidão permeou as falas e, tal expressão traduziu-se nas seguintes categorias: acolhimento e cuidado integral. A Figura 2, logo abaixo, trata de representar a "voz" de vinte nove (29) das sessenta e cinco (65) mulheres imigrantes que se sentiram acolhidas pelo serviço de saúde em Portugal durante o processo de parturição.
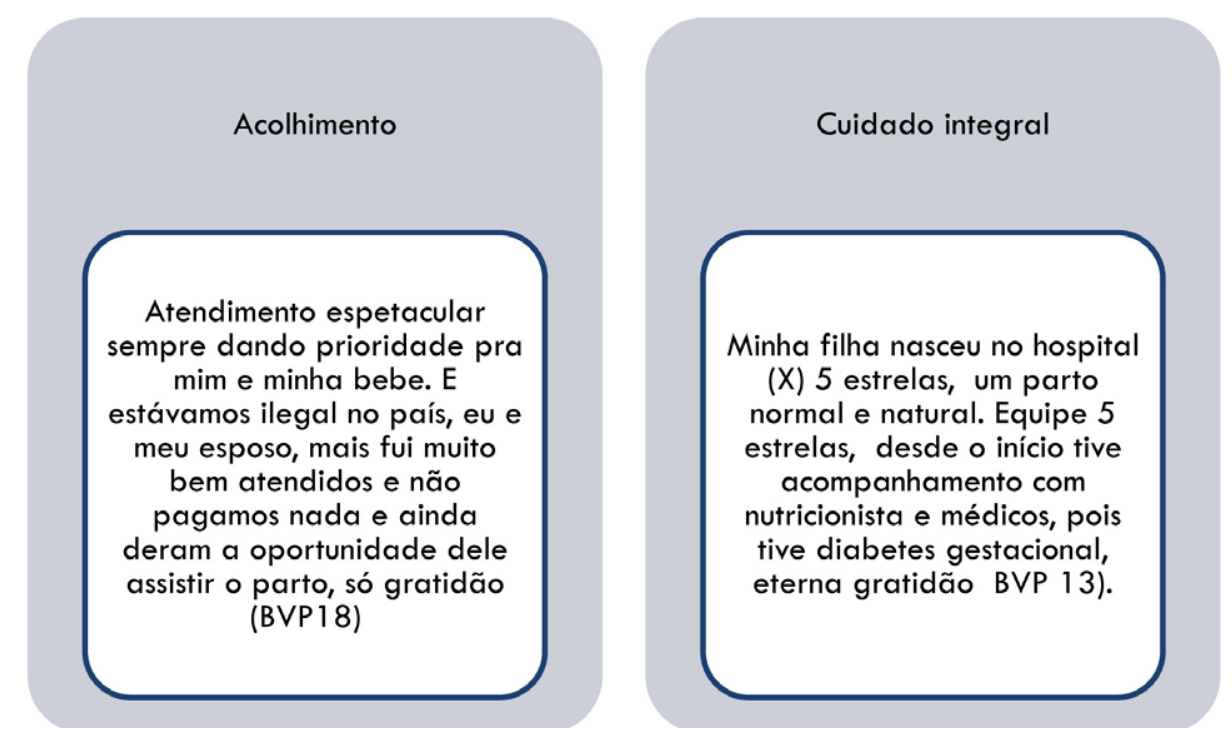

Figura 2: Categorias da unidade temática: não há no mundo exagero mais belo que a gratidão, Portugal, 2016. Fonte: elaborado pelos autores.

A partir das narrativas das brasileiras imigrantes elucida-se o sentido dessa unidade temática que é deflagrado por um sentimento ímpar de gratidão e acolhida. Fato que corrobora com dos dados de uma pesquisa realizada pela Associação Portuguesa pelos Direitos da Mulher na Gravidez e Parto ${ }^{14}$; em que a grande maioria das mulheres sentiu-se respeitada, ouvida, cuidada, apoiada e segura durante o seu parto, afirmando que os profissionais de saúde comunicaram de forma positiva e que o parto teve uma influência positiva na sua relação com o bebê.

As imigrantes grávidas passam por dois processos simultaneamente de transição. Por um lado, a imigração com as múltiplas transformações que a mesma implica, e por outro, o processo de transição que constitui o próprio 
tornar-se mãe. Ao se fazer a relação entre gravidez e imigração se está não só perante o fenômeno da integração das mulheres imigrantes no corpo social das instituições de apoio, do diálogo, mas também da interdição e incompreensão de práticas sociais e das transformações dos significados do corpo, da religião e crenças, das tradições de cuidados à saúde.

As investigações empíricas recentes revelam que a discriminação étnica e o preconceito desempenham um papel fundamental na adaptação dos imigrantes e que tais experiências comprometem sua saúde física e emocional ${ }^{15}$. Neste sentido os cuidados voltados para imigrantes gravidas devem ser intensificados.

Os relatos das brasileiras neste item encontram "eco" de acordo com o previsto nas leis portuguesas, ou seja, tiveram acesso ao sistema nacional de saúde e mostram-se agradecidas pela forma como receberam cuidados durante seus partos.

Importante mencionar ainda um contra ponto ${ }^{16}$; 0 acesso aos cuidados de saúde deve ser percebido como um conceito multidimensional que integra, por um lado, os direitos aos cuidados de saúde consagrados na lei e, por outro lado, a capacidade que as imigrantes têm de deles fazer uso. Já em Portugal, como em geral acontece em outros países, parece existir uma discrepância entre aquilo que é a dimensão legal dos direitos das imigrantes no setor da saúde e a capacidade real de reivindicalos. Na realidade, apesar dos avanços legais dos últimos anos, o acesso aos cuidados de saúde não é - mesmo para autóctones e imigrantes e, no que a este último grupo diz respeito, não é o mesmo para imigrantes regulares e irregulares. Neste sentido, - acesso deve variar, na prática, em função do estatuto legal, do tempo de residência no país e da nacionalidade de cada um, entre outros fatores.
Ainda contrariamente aos achados de nossa pesquisa autores ${ }^{3}$ mencionam que estudos sugerem, na realidade, que as mulheres migrantes se deparam com enormes desafios quanto ao acesso aos cuidados de saúde. As dificuldades parecem intensificar-se nos domínios da saúde sexual e reprodutiva, sendo a gravidez e a maternidade períodos de maior vulnerabilidade à doença e ao risco, para elas e para os seus descendentes. Segue afirmando, que os resultados das investigações desenvolvidas nesta área apontam no sentido dos profissionais de saúde não estarem devidamente preparados para atuar junto de populações de imigrantes.

\section{A diferença entre sucesso e fracasso é trabalho com competência}

A máxima representada na temática acima se baseia na formação por competência e, consequentemente, na forma como os profissionais de saúde a executam. Dispor de conhecimento, habilidade e atitude que contribuam para $\circ$ cuidado integrado humanizado que pode fornecer o reconhecimento e, mais que isso, a qualidade da assistência prestada. Então, tal unidade temática destaca a percepção que as mulheres imigrantes brasileiras possuem sobre os profissionais de saúde que assistiram seu parto. Doze (12) das sessenta e cinco (65) mulheres entrevistadas referiam em suas narrativas palavras que denotavam a empatia, a competência profissional e a experiência desses profissionais na condução do parto.

Pode-se sugerir que estas percepções possuem como referência seu país de origem, assim, ao compararem a assistencia recebida no Brasil, com as que estam recebendo em Portugal, demonstram satisfação e evidenciam em seus relatos os motivos. A Figura 3 abaixo, apresenta 0 extrato de falas que são contempladas nesta categoria. 

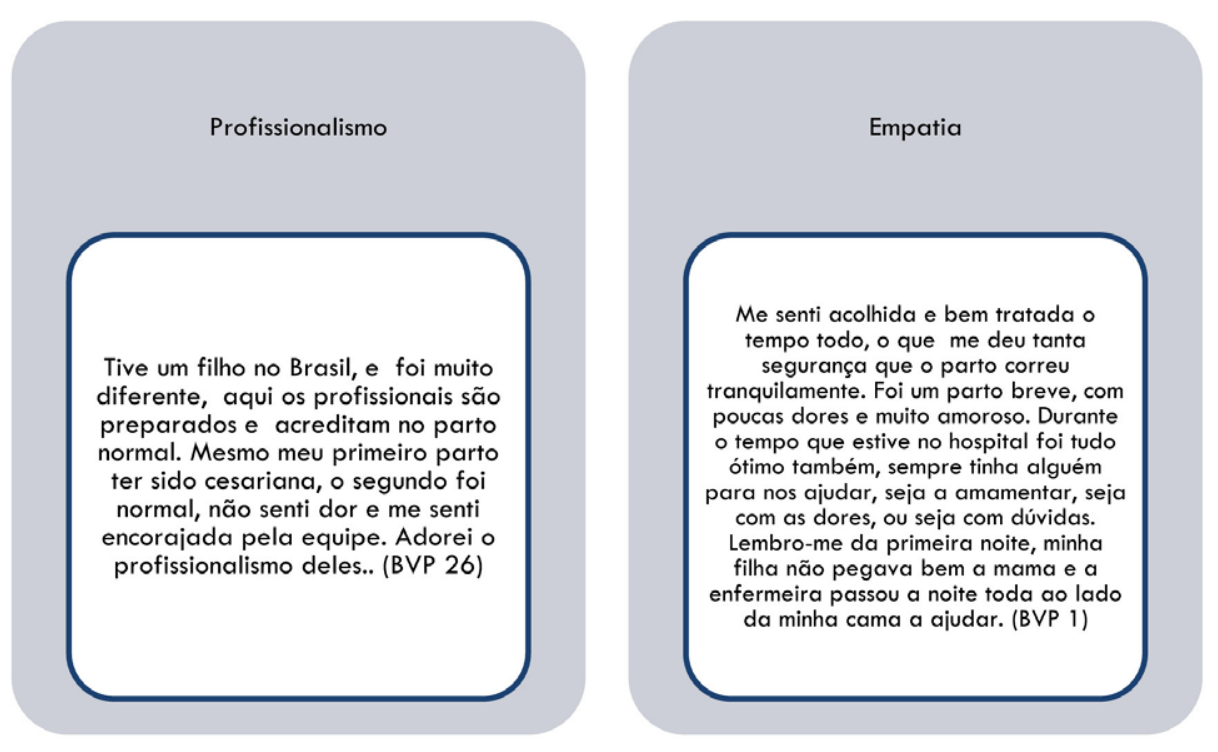

Figura 3: Categorias da unidade temática: a diferença entre sucesso e fracasso é trabalho com competência, Portugal, 2016.

Fonte: elaborado pelos autores.

As falas acima pontuam o retorno satisfatório da qualidade da assistência. Fato positivo na medida em que o medo da falta de profissionalismo de saúde pode ser considerado um dos principais indícios do medo do parto normal. ${ }^{17} \mathrm{E}$ isso, muitas vezes, pode contribuir para o desejo de cesariana, a consequência mais referida nos estudos é a preferência, ou pedido, por cesariana ${ }^{18}$.

Contrapondo-se a esse medo no ato de parir, este estudo exaltou a satisfação no ato de parir em Portugal, reconhecendo positivamente o trabalho dos profissionais da área da saúde portugueses. Tal concepção, vivenciada por algumas brasileiras que residem em Portugal, apresenta coerência com os dados encontrados em outra pesquisa 10 onde a satisfação manifestada pela grande maioria das participantes, decorreu do fato dos cuidados de saúde atenderem às suas necessidades. Para várias imigrantes que viviam em Portugal, estes cuidados superaram as suas expectativas, ao compará-los com os de seus próprios países, com destaque para a gratuidade. Para as gestantes, de um modo geral, a dimensão afetivo-relacional foi considerada importante nesta fase de suas vidas. Neste contexto, existe o destaque para os/as enfermeiros/as, com os quais as mulheres mantiveram maior contato.

Os cuidados de saúde durante a gravidez englobam quatro categorias relativas às dimensões afetivorelacional, cognitiva, técnico-instrumental e política do cuidado $^{10}$. Assim como em nossa pesquisa, a dimensão afetivo-relacional aparece de forma expressiva, estando relacionada à relação de confiança entre profissionais de saúde, mais das áreas da medicina e enfermagem e as gestantes trazendo o diálogo franco, apoio, interesse, conforto, bom acolhimento e atenção recebidos destes profissionais em saber que poderiam contar com eles em qualquer situação. Esta dimensão do cuidado foi muito significativa para elas, principalmente por se sentirem fragilizadas e inseguras com esta nova condição. Assim, para as imigrantes, o cuidado foi vital por estarem longe de seu país de origem e de sua rede de apoio.

\section{Não há nada mais duro que a suavidade da indiferença}

Essa unidade temática representa $\circ$ grupo de mulheres imigrantes brasileiras no ato de parir que não se satisfizeram com os serviços de saúde de Portugal. Ela representa seis (6) das sessenta e cinco mulheres (65) que participaram do estudo. Uma amostra pequena, porém significativa pelo teor e profundidade das informações colhidas.

Nesta dimensão, os aspectos negativos emergiram nas seguintes categorias: Onde estava a humanização? E Negação do poder de decisão. Os relatos denunciam uma assistencia de baixa qualidade e acesso inadequado aos serviços de saúde de Portugal. 


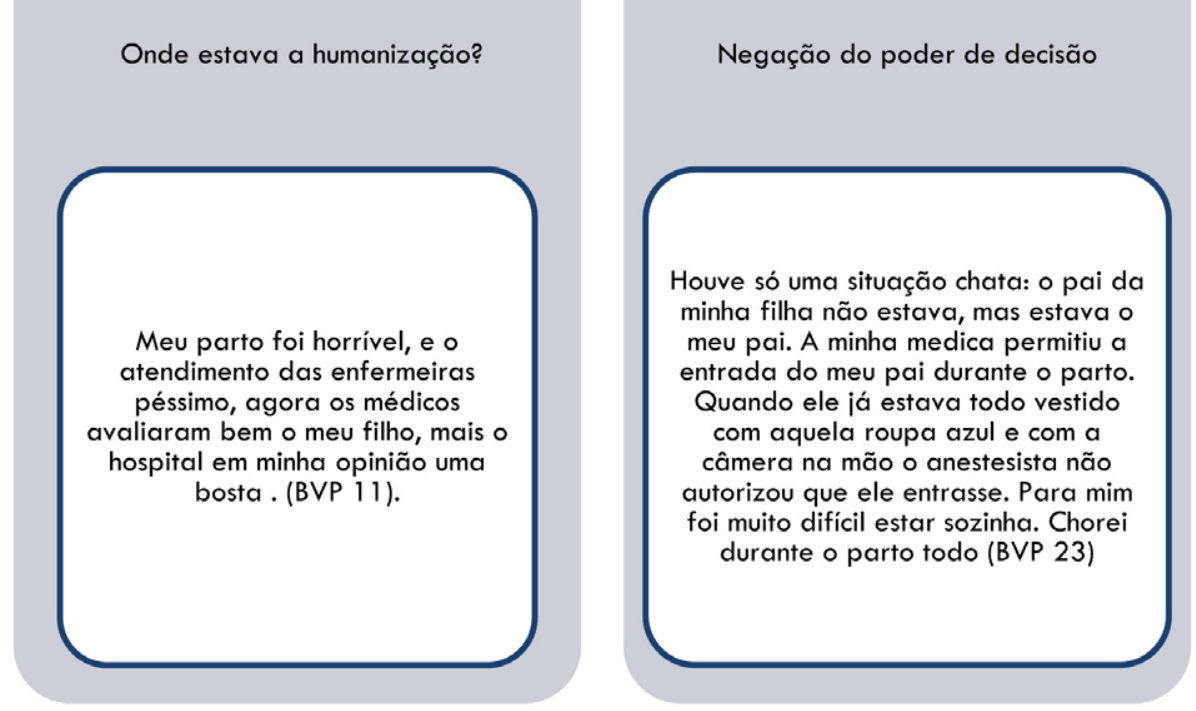

Figura 4: Categorias da unidade temática: a diferença entre sucesso e fracasso é trabalho com competência, Portugal, 2016.

Fonte: elaborado pelos autores.

A categoria onde estava a humanização? Explana uma assistência que mecaniza o parto, percebe-se de forma clara a inobservância da humanização e da compreensão dos sentimentos das imigrantes brasileiras, sobretudo na hora do parto. Segundo elas, faltou considerar além da distância dos parentes e familiares, da insegurança que o próprio momento traz consigo, o não sentir-se acolhida, estar 'a mercê' de um conjunto de regras impostas por desconhecidos em um lugar "alheio" reforçando o sentimento de "intrusão", por vezes inferidos pelas falas constituintes desta categoria.

Considerando que o parto é um processo fisiológico, a mulher não pode deixar de ser a principal protagonista neste processo, embora careça ser manipulada e orientada por profissionais aptos para atender as demandas físicas, sua autonomia, confiança e bem estar reverberam sobremaneira em sua desenvoltura e menor risco de complicações ${ }^{19}$. Dito isso, afirma-se que o acesso aos cuidados de saúde deve ser compreendido em uma perspectiva multidimensional integrando, por um lado, os direitos aos cuidados firmados no Despacho $n^{\circ} 25$ $360 / 2001$, por outro lado, a capacidade que os (as) imigrantes têm de deles fazer uso ${ }^{4}$.

A humanização na assistência ao parto como a organização de uma atenção de qualidade, voltada às necessidades físicas e psicológicas das parturientes e sua família, é ressaltada pelo Ministério da Saúde enquanto condição basilar à atenção humanizada e integral. Autores ${ }^{19}$ relatam que 0 medo, estresse, tensão, frio, fome, solidão, desconhecimento sobre o trabalho de parto, desamparo social e afetivo, além do fato de estar em ambiente diferente com pessoas estranhas são considerados fatores que colaboram intensamente para a percepção dolorosa no parto.

Há de se considerar que na condição de imigrante, - acesso e a utilização dos serviços de saúde podem ser condicionados por diversos obstáculos e ou barreiras, como, os legislativos, estruturais, econômicos e culturais. Compreende-se que tais barreiras interferem de forma significativa no processo de parturição, uma vez que, o momento do parto pode trazer experiências negativas que afetem a saúde física e mental.

Em estudo de revisão sobre a saúde de imigrantes brasileiros, os autores ${ }^{20}$ identificaram que a saúde mental dos imigrantes vem sendo abordada nos artigos como uma das áreas mais atingidas e como um dos principais problemas de saúde. Estes se desenvolvem ao longo dos anos de vida no exterior, podendo ocorrer nos primeiros anos durante $\circ$ processo de adaptação.

Neste contexto, assiste-se a uma dificuldade por parte de alguns técnicos de saúde em ter em conta os sistemas de crenças das comunidades imigrantes, que envolvem os comportamentos sexuais e reprodutivos, além de apontarem a ausência de sensibilidade dos profissionais de saúde sobre os 
hábitos e costumes das minorias étnicas como fator influente na utilização dos serviços.

Foram citadas barreiras como: o longo tempo de espera para serem atendidas; a falta de vigilância da gravidez no domićlio; a falta de acompanhamento por um especialista; 0 acesso demorado às consultas no centro de saúde; a falta de acompanhamento pelo mesmo médico e a falta de organização no centro de saúde e hospital.

Pintassilgo ${ }^{21}$ em sua tese de doutoramento: o risco e as condições sociais e assistenciais da maternidade em Portugal faz a seguinte afirmação nas considerações finais. "Um novo padrão assistencial no nascimento implica transformações sociais a diferentes níveis. As verdadeiras protagonistas desses acontecimentos, as mulheres, terão que desejar essas transformações, assumindo a natureza do processo". Porém, vale uma reflexão: será que a condição de mulher imigrante, com todos seus condicionantes conhecidos, permitirá este protagonismo desejado?

Pelo que foi descrito o poder de decisão foi negado. O desejo da brasileira imigrante, ou melhor, sua autonomia em decidir quem estará presente em seu parto deu lugar a uma mulher com posição desprivilegiada, ou seja, num cenário de passividade, negando sua autonomia e a privando de um parto humanizado.

O parto passou a ser algo cercado de uma prática intervencionista em que a mulher, perdendo o protagonismo, também "[...] perdeu gradualmente seu direito de escolha"22. É sabido ainda que mesmo existindo um grande número de tecnologias que visam atender a mulher no trabalho de parto, essa assistência nunca será excelente se negar a autonomia e desrespeitar o desejo da mulher. Carecemos ainda de postura ética do profissional com atitudes acolhedoras e humanas uma vez que, mesmo que se minimizem as sequelas físicas, as psicológicas poderão ser perenes.

Diante desta contextualização e compreensão das experiências de partos entre as imigrantes brasileiras em Portugal, é fundamental ressaltar a importância de outros estudos que articulem as formas acesso, assistência, acolhimento no sistema de saúde português.

\section{Implicações para enfermagem}

A maternidade e a imigração podem ser consideradas fenômenos de transição na atualidade, muito vivenciados por mulheres que procuram melhores condições de vida. $O$ acesso aos cuidados de saúde é um dos maiores obstáculos que os imigrantes enfrentam nos países de acolhimento. Porém é sabido que o direito à saúde é universal, e fundamental, não independente de sua nacionalidade, língua, religião ou opção politica.

A importância da Enfermagem na assistência direta ou indireta ao parto é um fato. Os cuidados relacionados à mulher imigrante devem ser singulares, levando em consideração seus aspectos culturais e suas particularidades. Recomenda-se o atendimento de sete atividades para que este cuidado seja eficaz: 1. proporcionar à gestante a informação necessária sobre a gravidez, o parto e o recémnascido, de modo que possa viver conscientemente esse momento tão especial; 2 . vencer a ansiedade e o medo transmitidos de mães para filhas, para que a dor física não seja ampliada pela angústia; 3. reduzir ao mínimo a dor; 4. ensinar a colaborar com o próprio corpo para que tudo decorra da forma mais fácil e rápida possível; 5. proporcionar o encontro com outras mulheres na mesma situação e que podem oferecer a sua colaboração e solidariedade; 6. dar, em muitos casos, ao futuro pai a informação e os conselhos necessários para que em todos os momentos, incluindo o do parto, possa estar o mais perto possível da futura mãe ${ }^{7}$. apresentar à mulher os ambientes em que irá estar internada e onde será assistida, para que lhe sejam menos estranhos ${ }^{23}$.

O enfermeiro deve conhecer a situação da parturiente, para poder interpretar e obter uma compreensão informada do seu sofrimento. Essa compreensão objetiva selecionar estratégias mais adequadas para resolver as questões que envolvem a futura mãe, assim como quais os cuidados se deve ter.

Finalmente vale lembrar que os Direitos da Mulher na Gravidez e Parto devem ser garantidos, todas as mulheres têm direito a serem bem tratadas e estarem fora de perigo onde quer que estejam. Neste sentido a enfermagem deve está preparada para garantir este direito que é universal. 


\section{CONSIDERAÇÕES FINAIS}

O estudo focou narrar as experiências da assistência em saúde durante o parto de imigrantes brasileiras que vivem em Portugal. Assim tendo em consideração tal objetivo e os achados desse artigo, há que se referir: Um quantitativo maior de mulheres brasileiras imigrantes em Portugal ressaltaram mais pontos positivos do que negativos na assistência ao parto. Fato confirmado nas três das quatro unidades temáticas analisadas. Foi narrado pelas mulheres brasileiras imigrantes em Portugal que durante seu parto foi possível encontrar acolhimento, escuta, profissionalismo e empatia por parte da equipe técnica de saúde.

Apesar de ser uma amostra pequena, seis (6) mulheres imigrantes brasileiras apresentaram uma narrativa penosa sobre o ato de parir em Portugal. Essas mulheres sentiram-se desassistidas e porque não dizer desumanizadas no serviço de saúde Português.

Assim, uma vez que as vivências positivas prevaleceram, o parto normal e a humanização durante o trabalho de parto foram credencias que apoiam a qualidade evidenciada nas experiências relatadas.

Diante disso, o que dizer sobre o parto de brasileiras em Portugal? $O$ espaço institucional e de atuação profissional, podem fazer a diferença quando atuarem tendo como base as principais necessidades da população de imigrantes e que o nascimento de um filho é um momento importante na vida de uma mulher, podendo ser decisivo na forma como esta se posiciona perante si própria e perante a sociedade, a depender do processo vivenciado. Em geral, as experiências negativas permanecem causando efeitos nocivos.

Assim, neste fenômeno migratório é primordial estudos mais aprofundados sobre os itinerários de mulheres grávidas e os desfechos sobre seus partos, ou mais que isso, em seu puerpério ou até sofrimentos que reverberem em uma vida, conotando a experiência do parto como algo ruim e doloroso. Com isso, mostra-se necessária uma identificação mais detalhada das insatisfações, e vulnerabilidades dos cuidados dispensados a estas populações especificas.

O estudo, ainda, sugere a criação de um observatório sobre pré-natal, parto e puerpério de imigrantes brasileiras sob a coordenação dos Consulados do Brasil em Portugal. Este seria uma importante ferramenta de monitoramento sobre os processos assistências envolvendo a mãe e seu filho. Construído com informações de alguns indicadores relativos às 03 fases. 1) Pré-natal - número de consultas realizadas, tipos exames realizados e ultrassonografia em tempo oportuno, avaliação da vulnerabilidade e risco - atendimento diferenciado para as situações de risco e promoção da vinculação ao local do parto, 2) Parto - tipo de parto, direito a acompanhante durante a internação, oferta de métodos de alívio da dor, contato pele a pele mãe - bebê e acolhimento adequado às especificidades étnico-culturais 3) Puerpério - acesso à informação e aos métodos contraceptivos.

Dito isso, esclarece-se que o estudo apresenta alguns fatores limitantes, entre eles: tipo de abordagem metodológica, o que representou apenas um universo especifico de um determinado grupo de imigrantes brasileiras, pois estas possuem acesso a internet $e$ estão ativamente participando da comunicação virtual, sendo assim, puderam enviar seus relatos para o grupo; entretanto não minimiza-se os efeitos que esse achado científico pode efetuar sobre o objeto em questão, privilegiando assim a prática baseada em evidência.

\section{CONFLITOS DE INTERESSES}

\footnotetext{
Nenhum conflito financeiro, legal ou político envolvendo terceiros (governo, empresas e fundações privadas, etc.) foi declarado para nenhum aspecto do trabalho submetido (incluindo mas não limitando-se a subvenções e financiamentos, conselho consultivo, desenho de estudo, preparação de manuscrito, análise estatística, etc).
} 


\section{REFERÊNCIAS}

1. Dias P, Machado R, Oliveira A. Relatório de Imigração, Fronteiras e Asilo. Barcarena; Serviço de Estrangeiros e Fronteiras, 2015.

2. Organização Mundial de Saúde. Prevenção e eliminação de abusos, desrespeito e maus-tratos durante o parto em instituições de saúde [Internet]. 2014 [acesso em 2016 nov. 13]. Disponível em: http://apps.who.int/iris/ bitstream/10665/134588/3/WHO_RHR_14.23_por.pdf

3. Topa J, Neves S, Nogueira C. Imigração e saúde: a (in) acessibilidade das mulheres imigrantes aos cuidados de saúde. Saúde Soc. 2013;22(2):328-341. doi: 10.1590/ s0104-12902013000200006

4. Portugal. Ministério da Saúde. Despacho $n^{\circ} 2536$, de 16 de Novembro de 2001. Diário Oficial da Republica Federativa de Portugal [Internet]. 2001 [acesso em 29 de agosto de 2016]. Série 2. p. 20597-98. Disponível em: http://www.acss.min-saude.pt/Portals/0/25360_2001.pdf

5. European comission. Report on health inequalities in the European Union. Brussels; Commission staff working documen, 2013.

6. Direção Geral da Saúde. Os riscos acrescidos da cesariana [Internet]. 2015 [acesso em 2016 ago. 12]. Disponivel em: https://www.dgs.pt/em-destaque/normae-orientacoes-sobre-aspetos-tecnicos-relacionados-com-acesariana.aspx

7. Amaral A, Natal G, Viana, L. Netnografia como aporte metodológico da pesquisa em comunicação digital. Revista Sessões do Imaginário. 2008; 13(20):34-40.

8. Minayo, MCS. O desafio do conhecimento: Pesquisa qualitativa em saúde. Ciênc. saúde coletiva. 2007; 1 2(4):342-44.

9. Brasil. Ministério da Saúde. Resolução $n^{\circ}$ 466, de 12 de dezembro de 2012 . Regulamenta pesquisa envolvendo seres humanos. Diário Oficial da República Federativa do Brasil. 2012.

10. Coutinho E, Morais C, Parreira V, Duarte J. Contributos da Preparação para o Parto na Percepção de Cuidados Culturais. Millenium. 2014;47:21-32.

11. Cetin H, Gunay N, Dalak H. Traditional practices to women during pregnancy, birth and after birth and reasons. HealthMed. 201 2;6(7):2396-2406.
12. Pereira ALF, Bento AD. Autonomia no parto normal na perspectiva das mulheres atendidas na casa de parto. Rev Rene. $2011 ; 12(3): 471-7$.

13. Varela V. O Parto Normal em Portugal: a experiência de "parto na água" no Hospital de São Bernardo. COST Management Committee. 2013:141-51.

14. Associação Portuguesa pelos Direitos da Mulher na Gravidez e Parto. Experiências de Parto em Portugal Inquérito às mulheres sobre as suas experiências de parto. Lisboa; 2015.

15. Neto F. Estudos de psicologia intercultural - nós e os outros. 3.ed. Lisboa: Fundação Calouste Gulbenkian; 2008.

16. Fonseca ML, Esteves A, McGarrigle J, Silva S. Saúde e integração dos imigrantes em Portugal: uma perspectiva geográfica e política. Migrações. 2007;01:27-52.

17. Haines H, Pallant J, Karlström A, Hildingsson, I. Crosscultural comparison of levels of childbirth-related fear in Australian and Swedish sample. Midwifery. 2011 ;27(4): 56067. doi:10.1016/i.midw.2010.05.004

18. Alves CC, Cavalcante MMB, de Sampaio ACC, Aragão $\mathrm{HL}$, Oliveira EN, Teixeira MA. Humanização do parto a partir de métodos não farmacológicos para o alívio da dor: relato de experiência. Sanare. $2015 ; 14(2): 70-74$.

19. Davim RMB, Torres GV, Dantas JC. Efetividade de estratégias não farmacológicas no alívio da dor de parturientes no trabalho de parto. Rev. esc. enferm. USP. 2009;43(2):438-445. doi: 10.1590/S0080$\underline{62342009000200025}$

20. Oliveira EN, Neto FFM, Freire AS, Félix TA, Moreira RMM, Lima GF. Saúde de imigrantes: estudos com brasileiros baseados em evidências. Sanare. 2016;15(1):74-81.

21. Pintassilgo SIGC. O risco e as condições sociais e assistenciais da maternidade em Portugal [tese]. Lisboa: Instituto Universitário de Lisboa; 2014.

22. Pimenta LF, Ressel LB, Stumm KE. The cultural construction of the birth process. J Res: Fundam Care Online. 2013;5(4):591-8. doi: $10.9789 / 2175-5361.2013 v 5 n 4 p 591$

23. Couto GR. Conceitualização pelas enfermeiras de preparação para o parto. Rev. Latino-Am. Enfermagem. 2006;1 4(2):190-198. doi: 10.1590/S010411692006000200007 